analecta polit. | Vol. 9 | No. 16 | PP. 117-149 | enero-junio | 2019 | ISSN-e: 2390-0067 (en línea) |

Medellín-Colombia

doi: http://dx.doi.org/10.18566/apolit.v9n16.a07

\title{
La posmemoria: un elemento fundamental para la construcción de ciudadanía en Soacha*
}

Post-memory: a fundamental element for the construction of citizenship in Soacha

A pós-modernidade: um elemento fundamental na construção de cidadania em Soacha

\section{ANA MARÍA MONTES RAMÍREZ}

Magister en Estudios Políticos y Relaciones Internacionales

Universidad Militar Nueva Granada

Correo electrónico: ammonra58@hotmail.com orcid.org/0000-0002-4803-3579

\section{DAVID GONZÁLEZ CUENCA}

Cómo citar

este artículo en APA:

Montes, A. M.

González, D. y Molina-

Orjuela, D. E (2019).

La posmemoria: un

elemento fundamental para la construcción de ciudadanía en Soacha. Analecta Política, 9(16), 117-149.

Fecha de recepción: 25.09.2018

Fecha de aceptación: 09.04.2019
Magister en Relaciones y Negocios Internacionales

Miembro del Grupo de Investigación PIREO

Universidad Militar Nueva Granada

Correo electrónico: dagocrack@gmail.com

orcid.org/0000-0002-6563-9193

\section{DOUGLAS EDUARDO MOLINA-ORJUELA}

Magister en Desarrollo Rural

Miembro del Grupo de Investigación PIREO

Universidad Militar Nueva Granada

Correo electrónico: douglasemolina@gmail.com orcid.org/0000-0003-0788-9538

* Artículo resultado de Investigación: Inv-Dis 2477, denominada Regulación ambiental y paz; una visión de la participación de los jóvenes en el post-acuerdo para la protección del medio ambiente, proyecto de investigación adscrito a la Vicerrectoría de Investigaciones de la Universidad Militar Nueva Granada. 


\section{Resumen}

Este artículo intenta establecer los alcances de la posmemoria como elemento fundamental para la construcción de ciudadanía en Soacha, identificando las características propias del municipio a la luz de la llegada masiva de desplazados por cuenta del conflicto armado interno y las implicaciones en la construcción de identidad y sociedad que esto conlleva.

Se presenta como un ejercicio analítico innovador en la construcción de ciudadanía en Colombia, dado que la posmemoria es un elemento revitalizador de las estructuras sociales, donde se participa de identidades violentadas o reprimidas y pueden generar, mediante conductas de reconstrucción pacífica de la memoria, escenarios de reconciliación y perdón, lo que permitirá construir comunidades, ciudadanos más íntegros, responsables y comprometidos con la paz y la tranquilidad de Colombia.

Este estudio está basado en una metodología cualitativa y como instrumentos de investigación hace uso del análisis, la revisión documental y otras herramientas propias de la heurística.

Palabras clave: posmemoria, ciudadanía, desplazamiento, política pública, participación, paz.

\section{Abstract}

This article tries to establish the scope of post-memory as a fundamental element for the construction of citizenship in the municipality of Soacha. This is done by identifying the characteristics of the population in the light of the massive arrival of displaced people caused by the internal armed conflict and of the implications derived from this phenomenon in the construction of identity and society.

The study is presented as an innovative analytical exercise in the construction of citizenship in Colombia, given the fact that postmemory is a revitalizing element of social structures, where ravished or repressed identities are involved. These can generate scenarios of reconciliation and forgiveness through conducts of peaceful reconstruction of memory, thus allowing building communities of more integral, responsible citizens, who are committed to the peace and tranquility of the country.

This study is based on a qualitative methodology, and it uses research tools such as the analysis and the documentary review, along with other instruments proper to heuristics.

Keywords: postmemory, citizenship, displacement, public policy, participation, peace. 
Ana María Montes R., David González C. y Douglas Eduardo Molina O. | 119 La posmemoria: un elemento fundamental para la construcción de ciudadanía

en Soacha

\section{Resumo}

Este artigo tem o intuito de estabelecer o escopo da pós memória como um elemento fundamental para a construçâo da cidadania na cidade de Soacha, identificando as características do município à luz da chegada maciça de deslocados por Conta do conflito armado interno e as implicaçóes na construçáo da identidade e da sociedade que isso implica.

apresenta-se como um exercício analítico inovador na construção da cidadania na Colômbia, dado que a pós memória é um elemento revitalizante das estruturas sociais, onde está envolvida em identidades violentas ou reprimidas e pode gerar, através Comportamentos de reconstruçáo pacífica da memória, cenários de reconciliação e perdão, que permitirão a construção de comunidades, cidadãos mais completos, responsáveis e comprometidos com a paz e tranquilidade da Colômbia.

Este estudo é desenvolvido com base em uma metodologia qualitativa e como ferramentas de pesquisa é utilizada análise, revisão documental e outras ferramentas próprias da heurística.

Palavras-chave: pós-memoria, cidadania, deslocamento, políticas públicas, participação, paz. 


\section{0 | Ana María Montes R., David González C. y Douglas Eduardo Molina-Orjuela La posmemoria: un elemento fundamental para la construcción de ciudadanía en Soacha}

\section{Introducción}

La presente investigación es un trabajo en curso de índole cualitativa y deductiva en el que se busca establecer las características poblacionales de Soacha, determinando la relación del municipio con los problemas derivados del conflicto armado en Colombia. Por ello, se exponen las necesidades de lineamientos de política pública que puedan ser potenciados por la ciudadanía y que contribuyan a la generación de procesos de posmemoria. Dicha caracterización se realiza para el periodo 2015-2017.

De igual forma, en la construcción teórica hay un momento analítico que tiene el objetivo de analizar la construcción de ciudadanía en América Latina y Colombia, así como ver su importancia en lo local, teniendo en cuenta la participación ciudadana en dicho ámbito. Todo ello tiene como eje articulador la identidad del individuo y su contribución al ejercicio de la ciudadanía y a la disolución de conflictos por cuenta del surgimiento de procesos de posmemoria.

Lo anterior desemboca en el acápite final, que pretende identificar la importancia de las víctimas del conflicto armado que habitan en el territorio de Soacha, teniendo en cuenta la construcción de escenarios de paz a partir de la consolidación de procesos de identidad, ciudadanía y posmemoria.

\section{Un escenario dispuesto para la posmemoria}

El municipio de Soacha, perteneciente al departamento de Cundinamarca, está ubicado en la zona sur de la Sabana de Bogotá; cuenta con un área de $185 \mathrm{~km}^{2}$, de los cuales $25 \mathrm{~km}^{2}$ corresponden a área urbana y $160 \mathrm{~km}^{2}$ a área rural; es uno de los municipios colombianos con mayor desorden físico, espacial y ambiental, debido al crecimiento exponencial y a la llegada de población afectada por el conflicto armado. El crecimiento urbanístico sin ninguna planeación, el aumento de la minería ilegal, el deterioro de los humedales y los recursos hídricos son algunos de sus problemas.

El territorio soachuno da asiento a 393.009 habitantes; se encuentra dividido en seis comunas y dos corregimientos, en los cuales cerca de 5.289 personas han encontrado su modus vivendi en la zona rural (lo anterior se determinó con 
Ana María Montes R., David González C. y Douglas Eduardo Molina O. | 121 La posmemoria: un elemento fundamental para la construcción de ciudadanía

base en el censo realizado en 2003 por el Departamento Nacional de Planeación, información que se encuentra en la página de la Alcaldía de Soacha -2016-). Estos datos son oficiales, pero en 2018 el Gobierno nacional pretendió realizar un nuevo censo poblacional que ayudara a determinar la realidad de la población del municipio, debido a que en los últimos catorce años ha continuado su incremento de manera significativa.

Figura 1 Mapa político de Soacha

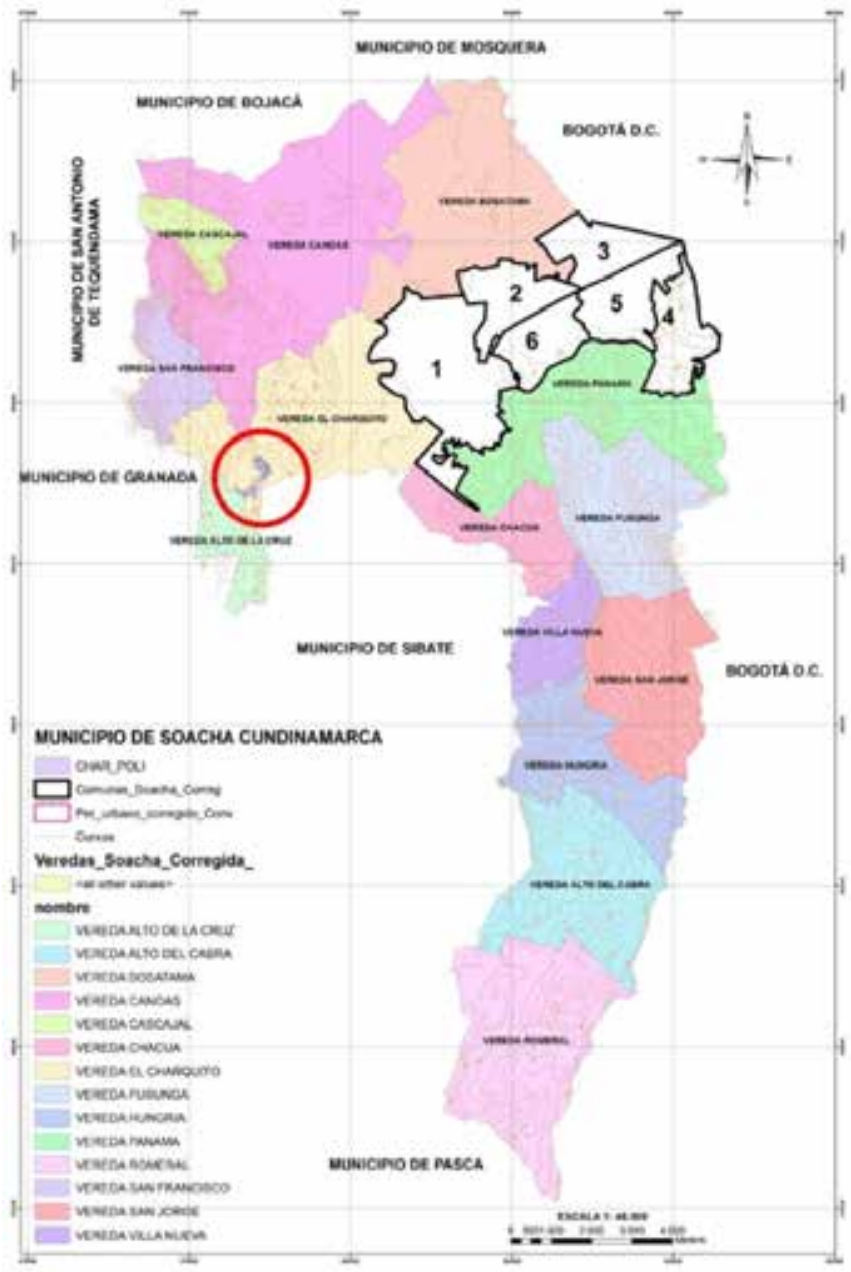

Fuente: Alcaldía Municipal de Soacha (2016). 


\section{2 | Ana María Montes R., David González C. y Douglas Eduardo Molina-Orjuela \\ La posmemoria: un elemento fundamental para la construcción de ciudadanía en Soacha}

La población del municipio lleva más de cuatro décadas viviendo un incremento visible, difícil de atender desde las políticas públicas locales y nacionales. Este incremento tiene origen en los problemas de desplazamiento forzado que afectaron a la población colombiana en las décadas de 1980, 1990 y 2000, y que determinaron la afluencia de población a la capital: Soacha fue el principal receptor de personas por la proximidad y la economía en el costo de vida comparado con Bogotá (Médicos Sin Fronteras -Quintero, 2013-).

Se evidencia, en los diferentes estudios realizados por la Gobernación de Cundinamarca, que este incremento poblacional en el municipio está directamente relacionado con la cercanía a Bogotá, pues aquellos ciudadanos que arriban a la capital en busca de mejores oportunidades para su desarrollo personal encuentran en el municipio condiciones de vivienda y manutención favorables, ya que el costo de vida en Bogotá es uno de los más altos del país.

En una entrevista realizada por los autores a una líder comunal raizal (Ramírez, 2017), se determinó que hasta la década de 1970 la actividad económica en el municipio se basaba en la agricultura y la ganadería, pero a finales de la década de 1980 se dio cabida a las grandes industrias. La llegada de Icollantas, Indumil y la organización del Parque Industrial de Cazucá fueron una estrategia del Gobierno municipal para generar empleo y por esa época comenzaron a darse importantes proyectos de vivienda con las urbanizaciones Compartir y San Mateo, las cuales, con posterioridad, se convertirían en los barrios más grandes por la proliferación de viviendas de interés social (Montes, González \& Molina, 2017).

De igual forma, en la entrevista se expuso que a principios de 1990 apareció el transporte público como negocio, con un alto coeficiente de empleabilidad. Así, surgieron rutas estratégicas que permitieron el ingreso de los soachunos a Bogotá, lo que hizo posible que la población del municipio accediera a educación superior y que gran parte de esta pudiera emplearse en la capital.

Por todo lo anterior, se ha consolidado un amplio porcentaje poblacional que, pese a tener residencia en Soacha, se encuentra domiciliado en Bogotá por ejercer su actividad laboral y comercial allí.

Aunado al crecimiento poblacional producto del crecimiento urbano, se presenta un aumento demográfico derivado del conflicto armado, pues, dada la cercanía de Soacha con la capital, aquellos que han huido de la violencia han llegado allí en las últimas cuatro décadas y han encontrado espacios más accesibles, económicos y próximos a las fuentes de empleo que ofrece Bogotá. 
Con la población en situación de vulnerabilidad derivada del desplazamiento forzado llegaron los problemas propios del conflicto; ello se arraigó en la población y propició los asentamientos humanos ilegales en zonas de alto riesgo geológico (antiguas minas de arena, las cuales hacen que la comuna IV, comprendida en los barrios de Cazucá y Ciudadela Sucre, sean bombas de tiempo que pueden ocasionar una tragedia en el evento de un deslizamiento o un deslave producto de un sismo o un aumento pluvial).

La conurbación con frecuencia permite la interacción de dos o más entidades territoriales, lo que crea dinámicas especiales en materia de políticas públicas, crecimiento económico y soluciones a problemáticas conjuntas. Medellín, por ejemplo, guarda un vínculo importante con los municipios de Envigado, Bello e Itagüí, pero Soacha es un problema para Bogotá -como lo ha observado en varias declaraciones públicas el burgomaestre capitalino-.

Por lo anterior, el principal factor de cambio y la principal problemática del municipio radican en el crecimiento demográfico desmesurado, lo que se encuentra determinado por los problemas nacionales de orden público y seguridad y genera, a su vez, problemas relacionados con el desarrollo social y los derechos humanos de la población que carece de recursos para asegurar un modo de vida en condiciones mínimas de dignidad.

Con base en el documento "Línea base para el estudio prospectivo del municipio de Soacha”, realizado por la Gobernación de Cundinamarca (2009), puede decirse que hay una marcada clasificación de la población soachuna: por un lado, se encuentran los soachunos raizales, que forman parte de familias que llevan más de treinta ańos habitando el territorio, ciudadanos que se asientan, en su mayoría, en las comunas II y XI (en estas comunas encontramos los barrios más antiguos del municipio y en estas familias radica la tradición oral y la historia inmaterial); y, por otro lado, la población itinerante o los pobladores ocasionales que se encuentran en el municipio a la espera de que su situación financiera se robustezca, momento en que planean movilizarse a un sector de la capital que les permita mejorar la calidad de vida en cuanto a seguridad y cercanía con sus sitios de trabajo o estudio (los cuales se encuentran, por regla general, en Bogotá).

Por lo anterior, el crecimiento demográfico es superior a la capacidad de la administración para planear las necesidades de la población itinerante, pues se requiere vocación de permanencia para la creación de un sentido de pertenencia que garantice la participación de la ciudadanía en el diseño y la implementación de las políticas públicas. Uno de los principales problemas es el desarraigo de los 


\section{4 | Ana María Montes R., David González C. y Douglas Eduardo Molina-Orjuela \\ La posmemoria: un elemento fundamental para la construcción de ciudadanía en Soacha}

moradores debido a la apatía ciudadana, lo que limita la aplicación de los proyectos municipales.

Se debe tener en cuenta que la población que ha incrementado la densidad poblacional del municipio se caracteriza por estar en situación de vulnerabilidad por condición de desplazamiento; su presencia en el municipio representa la generación de asentamientos humanos irregulares, erigidos en zonas de riesgo geológico, cuya inestabilidad impide la legalización de servicios públicos y el acceso lícito a la propiedad. Tal situación se evidencia en la comuna $\mathrm{V}$, que está compuesta por los territorios conocidos como Cazucá y Ciudadela Sucre.

En la vigencia 2014, se tiene el registro de 4.200 personas que se asentaron en el territorio soachuno, las cuales se encontraban en situación de discapacidad originada en el desplazamiento de su territorio de origen por cuestiones relacionadas con la violencia en Colombia. La atención a esta población requiere la confluencia de esfuerzos nacionales, departamentales y municipales, asistencia social proporcionada por el Estado que no puede ser evaluada debido a que un alto porcentaje de los ciudadanos beneficiados regresan a su territorio original o buscan mejorar sus condiciones de vida en Bogotá, como se mencionó antes.

Una de las políticas nacionales que más impacto ha tenido en el municipio es la generación desmesurada de vivienda de interés social, lo cual, pese a que crea vivienda y posibilidades de constitución de patrimonio familiar para muchos ciudadanos, no se encuentra orientado directamente a la población que habita el municipio. Esto implica un nuevo desplazamiento de ciudadanos que buscan acceder al beneficio de vivienda derivada de la política del Gobierno nacional.

De forma complementaria, el incremento de vivienda urbana -que no se encuentra en la planeación municipal-sobrepasa la cobertura en servicios públicos y expone a los ciudadanos al riesgo de que los servicios contratados por las unidades sean consumidos en un tiempo menor al presupuestado y, por lo tanto, deban enfrentar el racionamiento o la suspensión del servicio hasta la reactivación del siguiente periodo (Médicos Sin Fronteras, s. f.). En el caso específico del servicio del agua, este funciona con unidades (como un plan de telefonía celular, al terminar las unidades contratadas el servicio se congela hasta que se reinicia el siguiente periodo).

En el territorio no solo participan las entidades gubernamentales, sino que también contribuyen las organizaciones no gubernamentales como contratistas o ejecutoras de ayudas nacionales e internacionales. Sin embargo, como ya se 
indicó, este seguimiento es complejo por cuanto la medición del impacto requiere conocer la ubicación de los beneficiarios con posterioridad a la ejecución de las acciones públicas y privadas. La mayoría de los programas desarrollados para apoyar a este tipo de población se encuentran en el rango de la generación de empresa y la aplicación de proyectos productivos que buscan la perdurabilidad de los mismos para impactar positivamente la calidad de vida del grupo familiar (Cámara de Comercio de Bogotá, 2010). Lastimosamente, el modelo de acompańamiento psicosocial con que cuentan los proyectos productivos carece de un enfoque que permita un impacto en el individuo, que contribuya no solo a la reconciliación, sino a un redimensionamiento de la situación de las víctimas en la realidad nacional.

En Soacha no solo se requiere la activación de proyectos productivos para reconstituir la situación económica familiar, sino que se precisan proyectos sociales que garanticen la regeneración del tejido social y la creación de lazos que contribuyan a que el individuo establezca vínculos desde su propia necesidad para que esta sea un tópico que lo oriente a identificarse con sus congéneres y con el territorio en el que habita.

La detección de necesidades comunes es el punto de partida para la implementación de las políticas públicas; uno de los principales retos es crear vínculos entre los ciudadanos y su comunidad para que, de esta forma, se pueda orientarlos en el ejercicio de sus derechos políticos. El primer acercamiento con la creación de vínculos sociales se encuentra en las juntas de acción comunal.

Uno de los principales elementos de la pérdida de representatividad de la ciudadanía estudiados por Font (2004) radica en que los líderes comunales no son efectivos representantes de la comunidad, puesto que la ausencia de participación y la detección de necesidades conjuntas remite esta arena política únicamente al círculo de ciudadanos interesados en el trabajo comunitario y deja de lado a aquellos que no se sienten identificados y que, por lo tanto, no aceptarán la representatividad de quienes hubieran sido elegidos.

Se hace necesaria la participación de la ciudadanía en la institucionalidad; es primordial que esta participación (Molina Orjuela, 2014) repercuta en la legitimidad de la toma de decisiones y, por lo tanto, es importante que, de manera conjunta con la detección de necesidades, los ciudadanos se hagan partícipes de la implementación de soluciones y sean conscientes de su papel como parte de un grupo social que los necesita y valora, pese a que su estancia sea accidental y se pretenda una duración mínima en el territorio (Narváez, 2011). 


\section{6 | Ana María Montes R., David González C. y Douglas Eduardo Molina-Orjuela La posmemoria: un elemento fundamental para la construcción de ciudadanía en Soacha}

El ejercicio de la ciudadanía tiene unas contundentes implicaciones en la "agendación", formulación e implementación de la política pública. Las actuales tendencias tanto jurídicas como políticas pretenden que el individuo sea partícipe del proceso para que pueda entronizarlo, comprenderlo y acatarlo, lo que determina la posibilidad de una norma, producto de una necesidad, que sea generada tras un proceso consensual con el Estado (Montes, 2013).

La participación en la formulación e implementación de la política pública garantiza que los ciudadanos sean actores principales en la solución de las problemáticas de la comunidad en la que habitan; lamentablemente, la mayoría de las políticas implementadas son de origen gubernamental y su diseño y formulación pocas veces cuenta con la participación de la comunidad. Una de la forma de participación ciudadana son los cabildos abiertos o las acciones populares en procura de la defensa de los derechos colectivos.

Soacha debe contar con acciones que promuevan el ejercicio de la ciudadanía; el vínculo entre el individuo y el Estado es mucho más significativo que las políticas asistenciales, debido a que la relación de derecho crea un vínculo contractual que implica derechos y obligaciones recíprocas (Bodenheimer, 1940). Ese rango de responsabilidad individual permite que las personas dimensionen la importancia de su participación en el desarrollo de la comunidad en la que habitan.

La efectividad de la comunicación entre el ciudadano y el Estado garantiza la efectividad de la norma; es decir, un proceso de comunicación adecuado permite que el individuo tenga claridad sobre el planteamiento teleológico de la norma (cuál es el motivo para implementar la norma, cuál es su fin). De igual forma, al ser un planteamiento lógico, este conducirá a la aplicación de la misma por ser propio del comportamiento racional: ello es más eficaz que el mero cumplimiento de una imposición por temor a las represalias de la autoridad administrativa (Montes, 2013).

Los pobladores de Soacha, pues, se encuentran directamente relacionados con la violencia en Colombia; se trata de víctimas de las circunstancias económicas y sociales, campesinos en situación de vulnerabilidad por desplazamiento, pero también raizales que deploran el crecimiento desmesurado de su terruño y su falta de evolución en materia de políticas públicas y desarrollo.

Soacha es una población sin memoria, es la reunión de los errores en políticas de seguridad que se entremezclan con la falta de planeación y la ausencia de posibilidades claras de crecimiento económico; tanto la población originaria como 
aquellos que llegan buscando un mejor futuro requieren construir, en conjunto, un sentido de pertenencia que contribuya a la participación ciudadana y, con ello, a la construcción de un futuro conjunto (Quíles, 2014).

La memoria de los actuales habitantes es la memoria de un Estado que resume en sus últimos cincuenta años las necesidades y las prospectivas de solución, perdón y reconciliación, lo cual no se puede llevar a término sin el reconocimiento de las heridas que hacen parte de la historia de vida de las víctimas (Gallego, 2016).

Los hechos que han vulnerado los derechos fundamentales, en su mayoría, han sido perpetrados en otras poblaciones, pero las víctimas llevan consigo el dolor que trasciende el territorio y requieren no solo la reparación y la asistencia social, sino el tratamiento para empoderarlos y lograr que participen en las decisiones políticas. Soacha necesita ciudadanos que recuerden sus problemas y que, a partir de ellos, construyan un mejor futuro conjunto que permita sanar y continuar sin que el peso del pasado obstruya el camino hacia una mejor calidad de vida.

De lo anterior podemos concluir que Soacha tiene un sinnúmero de problemáticas que reflejan la realidad nacional y que, por lo tanto, evidencia una política pública que tiene problemas serios en cuanto a su ejecución y aplicación en lo local. Por ello se requiere analizar la construcción de ciudadanía en América Latina para lograr la apropiación de las políticas públicas por parte de los ciudadanos y las comunidades.

\section{Construcción de ciudadanía en América Latina}

Para la solución de las problemáticas sociales expresadas anteriormente en Soacha y en procura de garantizar un correcto ejercicio de posmemoria, se hace necesario comprender las dinámicas de construcción de ciudadanía en Latinoamérica. Así, durante el siglo xx América Latina estuvo marcada por luchas sociales tendientes a la ampliación de los derechos de ciudadanía y por procesos de reformas institucionales emprendidos desde el Estado como una forma de responder a diversas presiones sociales (García, 2000). Al terminar una prolongada etapa de dictaduras y represión en la región, las nuevas instituciones se encauzaron hacia la apertura democrática y la mayor inclusión de la población con el fin de no volver a permitir el surgimiento de regímenes autoritarios. 


\section{8 | Ana María Montes R., David González C. y Douglas Eduardo Molina-Orjuela La posmemoria: un elemento fundamental para la construcción de ciudadanía en Soacha}

En la actualidad, América Latina atraviesa un largo periodo de gobernabilidad democrática, paralelo a una dinámica económica de alta complejidad en términos de finanzas, tasas de inflación y deuda. Del mismo modo, se ha configurado una dicotomía referente a la aseveración de ciudadanía, al caracterizarse este concepto mediante pautas socioeconómicas y, así, condicionar las garantías de acceso a la genealogía de los derechos humanos. En esa medida, el ejercicio democrático, fundamental para la designación de autoridades en los países de la región, se ha visto obstaculizado por problemáticas que socaban el tejido social e instauran una sensación de desconfianza por parte de la sociedad civil hacia las instituciones públicas. Brechas de desigualdad, niveles insuficientes de voluntad pública, corrupción persistente y creciente inseguridad son algunos de estos fenómenos que han tendido a socavar el Estado de derecho (Levine \& Molina, 2011).

En este contexto, la concepción de modernidad en diferentes partes de América Latina parece estar inextricablemente ligada a las zonas de crisis, es decir, a los espacios de privación material, violencia y destrucción ambiental, así como a las exclusiones basadas en el género y la etnicidad. Es importante resaltar que algunos aspectos clave de la construcción de ciudadanía democrática a menudo se constituyen en zonas de crisis, tanto en términos de derechos legales como en las experiencias sobre el terreno de la ciudadanía vivida.

Este proceso de democratización incluye además la descentralización política para implementar un control más minucioso y concienzudo de las actividades gubernamentales, aunque no en todos los países ha sido implementada de manera homogénea. Asimismo, la transición democrática ha incluido procesos de participación ciudadana que, como afirma Sojo (2002), han tenido la finalidad de encarar los desafíos sociopolíticos que se presentaban en América Latina y restablecer los vasos comunicantes y las estrategias de gobernanza entre el Estado y la sociedad civil, estropeados a causa de las represiones ejercidas durante las dictaduras militares.

A pesar de lo anterior, en la población se ha presentado resquemor e inconformidad relacionada con la injusticia social y la exclusión política, problemáticas que no han sido resueltas en la mayoría de los países, lo que ha instado a fenómenos como movilizaciones, protestas y, en algunos escenarios, brotes de violencia que llaman la atención sobre las falencias de las democracias en América Latina (Donoso, 2015). Esta inconformidad se ha presentado debido a que, pese a las transformaciones democráticas que desarrollaron los Estados latinoamericanos, la naturaleza de cada uno continuó siendo la misma y limitó el establecimiento de políticas participativas. 
Actualmente, los problemas de democracia en América Latina se reflejan en el triángulo establecido por el PNUD (2004) entre la apertura democrática, la pobreza y la desigualdad. Lo anterior devela una brecha entre un modelo democrático y la historicidad política y social de los países, así como una brecha con el territorio; por ende, no se ha podido responder a la creciente desigualdad y pobreza, lo que a su vez ha generado una desconfianza general en la política como mecanismo para solucionar las problemáticas que conciernen a las comunidades en el ámbito local.

\section{Construcción de ciudadanía en Colombia}

Según muchos indicadores, en las últimas décadas se produjo un auge de la representación democrática en los Andes. Las políticas que excluían a las personas del ejercicio de la ciudadanía formal producían unas prácticas de representación truncada que se volvieron poco generalizadas. Más personas se convirtieron en ciudadanos en un sentido formal y menos fueron sometidas a formas tradicionales de dominación personalista. Surgió, entonces, un mayor número y diversidad de partidos. Sin embargo, junto a una mayor representación democrática surgió un creciente desencanto con las instituciones de representación (Mainwaring, 2006).

Colombia ha sido calificada como uno de los países políticamente más estables de la región, debido a que fue uno de los pocos que durante el periodo de dictaduras mantuvo un régimen democrático que fue evolucionando hasta hoy. De igual manera, durante el periodo de apertura democrática y política regional, Colombia fue el país que mayor profundidad dio a los procesos de descentralización (García, 2000). Sin embargo, este grado de apertura no se tradujo en un amplio nivel de participación política, lo que conllevó que diferentes grupos buscaran un cambio mediante la vía armada.

A diferencia de otros casos, en el país la descentralización fue una respuesta a la lucha insurgente y la crisis de legitimidad de los partidos tradicionales (García, 2000 , p. 24). Se consideró, entonces, que el funcionamiento más eficiente del sistema democrático y la gestión más participativa relegitimarían al Estado y sus instituciones, debido a que este comenzaría a representar las diversas expresiones culturales, sociales y ambientales que existían en el país. A pesar de que lo anterior conllevó grandes avances relacionados con la construcción ciudadana, cada vez más grupos e individuos reclamaron una mayor participación, en especial en la esfera política.

En medio de esta tensión entre ciudadanía y democracia participativa fue establecida la Constitución de 1991 por medio de la Asamblea Constituyente, en la 


\section{0 | Ana María Montes R., David González C. y Douglas Eduardo Molina-Orjuela La posmemoria: un elemento fundamental para la construcción de ciudadanía en Soacha}

que se incluyó no únicamente a los partidos tradicionales, sino también a miembros de exgrupos guerrilleros que habían desarrollado recientemente procesos de negociación con el Gobierno. Esta Constitución definió un nuevo marco de relaciones que transformó la concepción de Estado y otorgó a los ciudadanos un papel protagónico en la consecución de un mayor desarrollo (Alvarado \& Carreño, 2007, p. 3); no obstante, la misma no logró reducir la brecha entre ricos y pobres ni aumentar la participación de la ciudadanía a través de los mecanismos establecidos.

El país, actualmente, continúa con una amplia exclusión y polarización social que se reflejan en la concentración de ingresos ${ }^{1}$, la pobreza e indigencia ${ }^{2}$, la desigualdad estructural, la informalidad y precariedad laboral ${ }^{3}$, la baja cobertura en seguridad social y servicios básicos, y la exclusión de la nińez (Velázquez \& González, 2003, pp. 81-84). Cada uno de estos problemas demuestra que, como afirma Angulo (2013), la democracia en Colombia es ejercida por una élite que no tiene en cuenta la responsabilidad horizontal.

Adicionalmente, el marco legal establecido en la Constitución de 1991 sigue en una profunda tensión entre las normas vigentes y el conflicto interno armado, que se ha recrudecido con el pasar de los años. De esta manera, las instituciones formales han permanecido y el conflicto se ha vuelto inagotable (Velázquez \& González, 2003, p. 85), pero no se ha solucionado el problema de exclusión política, que fue la principal razón para que diferentes grupos decidieran acudir a la vía armada. Ambas áreas, pese a estar relacionadas, tratan de mantenerse al margen una de la otra, lo que imposibilita la transformación del conflicto armado en mayor y más diversa participación política.

Como resultado de esta situación, la crisis de representatividad en el país se ha agudizado, pues los ciudadanos ya no creen ni confían en los partidos políticos y, en cambio, han limitado su participación a la esfera individual o, en escasas ocasiones, colectiva (Angulo, 2013, p. 28). A su vez, esta apatía política facilita la persistencia de relaciones clientelistas y de la corrupción en las instituciones que hacen parte del Estado, problemas que terminan debilitando al Gobierno y limitando su campo de acción social. Se ha abierto, así, una brecha entre el ciuda-

1 Según los últimos datos publicadas por la Cepal, Colombia es el segundo país más desigual en la distribución del ingreso en la región (Neira, 2018).

2 En Colombia, la pobreza extrema aumentó su incidencia de 7,9\% en 2015 a 8,5\% en 2016 (Neira, 2018).

3 El informe final de la Comisión de Asuntos Sociales y laborales de la Ocde reconoce avances, pero establece que Colombia debe enfrentar la informalidad laboral, la desigualdad y la concentración del ingreso (Portafolio, 2018). 
dano y la esfera política pública (Velázquez \& González, 2003), pues este asocia la participación a una inclusión en la esfera política de la que tanto desconfía.

En resumen, aunque la constitución reconoce a los ciudadanos y ciudadanas como sujetos de derecho (Alvarado \& Carreño, 2007, p. 3), esto no se traduce en un acercamiento real con la ciudadanía ni en un cambiar de sentir y pensar de la misma frente a la política tradicional. Pese a que la Constitución colombiana estableció múltiples ideales que tuvieron como objetivo transformar la política y sus vicios históricos, los mecanismos para implementar dichos cambios siguen siendo limitados. El marco legislativo en Colombia se caracteriza por tener demasiadas leyes y normas, inclusive en el ámbito participativo, que no son aplicadas en un contexto real.

En palabras de Alvarado y Carreño (2007), para que la reconfiguración de la realidad social refleje lo establecido en la Constitución es necesario una transformación en el campo de acción de las instituciones, con el fin de permitir una mayor participación ciudadana y, adicionalmente, evitar que la poca participación existente se base en los intereses políticos de determinado partido para acceder a campos de mayor influencia en la política nacional. Es además importante, en palabras del autor, educar a los individuos para que se comprometan con la participación ciudadana como parte del proceso de construcción de sociedad (Alvarado \& Carreño, 2007).

Ese proceso de construcción de ciudadanía implica analizar que nuestra sociedad actual no es del todo saludable o que su propia supervivencia está amenazada por muchos problemas. También se entiende que la sociedad no percibe que sus estrategias e instituciones de resolución de problemas no funcionan bien. Entonces, es importante replantear, repensar y reconstruir la sociedad desde una visión holística. Se considera que la construcción ciudadana por parte de la sociedad civil es necesaria porque el sistema y las estructuras tradicionales parecen ser incapaces de lidiar con los problemas sociales actuales. Dicha construcción supone que se puede hacer algo para evitar que la sociedad colapse desde sus cimientos.

\section{Construcción de ciudadanía y su importancia en lo local}

En la última década del siglo xx resurgió la discusión en torno al concepto de "ciudadanía" y la importancia de esta en el mundo globalizado. Tal como lo afirma Cortina (1997), este concepto responde en la actualidad a una crisis identita- 


\section{2 | Ana María Montes R., David González C. y Douglas Eduardo Molina-Orjuela La posmemoria: un elemento fundamental para la construcción de ciudadanía en Soacha}

ria de las sociedades posindustriales, que acuden al mismo como mecanismo para sentirse parte de un espacio que adolece de cohesión. De esta manera, aunque el concepto de ciudadanía no es nuevo, este responde a nuevas necesidades de una sociedad en crisis, producto de un modelo democrático neoliberal que no ha podido garantizar la reducción de la pobreza y la desigualdad, así como la conservación del medio ambiente y la solución de los demás problemas ecosociales que continúan afectando a la humanidad (Cortina, 1997).

En ese orden de ideas, es necesario enunciar las dos tipologías construidas alrededor del concepto de ciudadanía, las cuales identifican, caracterizan y desarrollan de manera integral la forma en que se "desdobla" la condición del ciudadano respecto a las posiciones socioeconómicas, los privilegios socioculturales y algunas políticas sectarias y segregacionistas. Durston (1996) alude a una triada categórica sobre la ciudadanía que ejemplifica la incidencia de los factores étnicos, generacionales, sociales y económicos en el ejercicio significativo de la participación, el trato plural y los garantes al acceso de los derechos de manera integral. De esta manera, despliega los conceptos de "ciudadanía denegada", "ciudadanía de segunda clase" y "ciudadanía construida":

La ciudadanía denegada afecta a los comúnmente llamados sectores excluidos: etnias dominadas, pobres rurales, integrantes de los sectores urbanos de extrema marginación. A estos sectores se les niega la posibilidad práctica de ejercer ciudadanía por la discriminación racial, por la ausencia de espacios de participación dentro de su hábitat, y también por la falta de acceso al conocimiento necesario para la ciudadanía: por un lado, las destrezas de incorporación y análisis, por otro, la expresión de información relevante en un lenguaje que ellos manejan [...]. La ciudadanía de segunda clase es un concepto ampliamente utilizado para referir a aquellos sectores cuya ciudadanía no es negada explícitamente o totalmente, pero que enfrentan una serie de barreras sutiles que les dificultan su ejercicio. Los ejemplos sobresalientes son las mujeres -ciudadanos en sentido formal, pero inhibidas en la práctica para hablar en público y para expresar opiniones diferentes de los hombres $[\ldots .$.$] . La ciudadanía construida es un concepto que puede aplicarse,$ por ejemplo, a la necesidad de la sociedad y del Estado de construcción gradual de espacios, valores y actitudes favorables al ejercicio efectivo de la ciudadanía por todos los sectores. En este caso, sin embargo, nos referimos a la construcción gradual por el individuo de su propia ciudadanía mediante el aprendizaje de códigos y conocimientos y el ensayo práctico (Durston, 1996, pp. 3-4).

El sectarismo y la discriminación han permeado de manera estructural la condición del ciudadano y, en suma, la historia de la humanidad se ha caracterizado 
por la desigualdad (Abasolo \& Montero, 2012). Sin embargo, los cambios económicos y tecnológicos que han tenido lugar en las últimas décadas han producido una desigualdad sin precedentes. América Latina no ha sido la excepción frente a esta situación y es hoy en día la región más desigual del planeta; por esta razón, desde finales de los ochenta se ha desarrollado un debate regional acerca del rol de los ciudadanos en la construcción de una democracia más inclusiva.

Según Sojo (2002), la construcción ciudadana se ve reflejada de muchas maneras: esta aparece primero cuando un grupo de personas lleva a cabo un debate sobre la relación entre los individuos y el poder, para luego ser plasmada en un marco normativo de derechos y deberes que tiene el individuo en la sociedad y finalmente se refleja ideológicamente en la autoafirmación sobre el otro. Su uso en la región, por lo tanto, responde a un interés general de reconciliar los sectores políticos con los académicos mediante aportes para reformar el sistema político (Sojo, 2002, p. 32).

En el caso de Colombia, se afirma que estamos ante una crisis ciudadana (Angulo, 2013) reflejada en bajos niveles de discusión y participación política, contrarrestados por una fuerte desconfianza en lo institucional. Esta crisis ha sido producto de múltiples hechos históricos, de los cuales los más importantes son las disputas políticas y el conflicto interno armado, que han hecho el proceso de construcción ciudadana intermitente. De acuerdo con lo anterior, el objetivo del siguiente trabajo es analizar la importancia de la construcción ciudadana de Colombia en el ámbito local, para lo cual primero se abordará la construcción de la ciudadanía regional, después se estudiará el caso colombiano y, por último, se explicará la importancia que tiene la ciudadanía en los procesos democráticos locales.

\section{¿Cuál es la importancia de la participación ciudadana en el ámbito local?}

En el caso de la participación ciudadana, esta difiere tanto en el plano nacional como en el local, debido a que las lógicas sociales y políticas que presiden cada uno de ellos no están "armonizadas". Sin embargo, este tipo de participación es considerada la piedra angular de todos los procesos democráticos (Angulo, 2013); entonces ¿por qué es imperante la construcción de ciudadanía en el ámbito local? En el siguiente apartado se buscará responder este interrogante, teniendo en cuenta el proceso de construcción ciudadana en América Latina y Colombia. 


\section{4 | Ana María Montes R., David González C. y Douglas Eduardo Molina-Orjuela La posmemoria: un elemento fundamental para la construcción de ciudadanía en Soacha}

A pesar de que la Constitución de 1991 constituyó un gran avance frente a los derechos de participación de la ciudadanía, era poco lo que podía hacer la misma para fortalecerla si no se implementaban medidas adicionales para educar a la ciudadanía sobre sus derechos y deberes como sujetos políticos (Angulo, 2013, p. 36). El desconocimiento sobre estos derechos ha sido, por ende, una de las principales razones por las cuales, pese a ser Colombia una de las democracias más estables de América Latina, la participación ciudadana se ha estancado en la esfera política (además, la falta de implementación de garantías y mecanismos fácticos para garantizar la participación de la sociedad civil en tales procesos políticos generó por mucho tiempo que la Carta Magna fuera etérea en este respecto).

En ese orden de ideas, la exclusión histórica de los ciudadanos en la política ha conllevado un sentimiento general de apatía y desinterés por ella. Frente a tal problemática, la educación cívica es para Alvarado y Carreño (2007) la mejor alternativa para concientizar al ciudadano acerca de su rol en la sociedad y de cómo, desde su cotidianidad, puede transformar problemáticas con las que se siente inconforme. No obstante, es necesario que los ciudadanos, además de tomar parte en las deliberaciones y el debate político en busca de intereses particulares, también lo hagan pensando en la búsqueda del bien común y la construcción de una sociedad mejor (Angulo, 2013, p. 38).

La construcción de ciudadanía es, en consecuencia, fundamental para alcanzar procesos de justicia social en los cuales cada individuo reconozca sus derechos y deberes para establecer, así, mejores condiciones sociales en su territorio (Alvarado \& Carreńo, 2007). Al respecto, la educación permite al individuo concebirse a sí mismo como una persona que, mediante la vinculación con la comunidad, puede satisfacer sus intereses personales y generar un bienestar general. Todo lo anterior requiere un mayor compromiso del Gobierno y los ciudadanos desde ámbitos locales, reconociendo cada uno la importancia del otro en el proceso de fortalecimiento de las instituciones democráticas.

Según Galván (2011), la educación para la ciudadanía en el siglo xxi es un reto pendiente para la democracia y solo puede satisfacerse desde una perspectiva normativa. La participación ciudadana y la educación son, por lo tanto, dos elementos indispensables que deben estar regulados por un marco normativo fortalecido si se quieren alcanzar procesos de justicia social, especialmente en el caso colombiano -donde el desconocimiento de los derechos y deberes que se tienen como ciudadano se ven reflejados en la baja participación de las comunidades en asuntos que las afectan directamente (Galván, 2011)-. 
La participación ciudadana es el instrumento de desarrollo y empoderamiento social mediante el cual todos los actores de la sociedad pueden apropiarse de su desarrollo y crecimiento, tanto en términos económicos como sociales (Torres, 2011). Es la única vía para legitimar los sistemas políticos establecidos o reformarlos para solucionar los problemas estructurales que afectan a la población marginada. Es la mejor manera, además, de fortalecer las relaciones entre las comunidades y al interior de estas, por el hecho de fomentar la discusión desde varios puntos de vista y el respeto hacia el otro como actor importante en cualquier comunidad (Donoso, 2015).

Como lo afirma el PNUD (2004), una democracia que omite los problemas centrales vacía de contenido las opciones ciudadanas y transforma el mandato electoral en una expresión de voluntades sin consecuencias que no representan al electorado (p. 4). Por esta razón, la participación local juega un papel central en la construcción ciudadana, que, más allá de los procesos electorales, debe preocuparse por recuperar su papel central en la lucha para terminar con la pobreza y la desigualdad.

Por ello es ineludible visibilizar y dignificar con ahínco el papel de la participación ciudadana en un escenario posterior a la Constitución del 91, teniendo presentes las reformas que se han presentado al texto constitucional y el empoderamiento mediante ejercicios, procesos y mecanismos de participación ciudadana dados desde las comunidades de manera autónoma e independiente a la institucionalidad gubernamental. Ahora bien, es trascendental interpretar que del espíritu y del texto original queda poco, y que en muchos casos se ha intentado fortalecer la participación con mecanismos políticos (que han sido ampliamente limitados en algunas reformas constitucionales).

De tal forma que, al entender cómo fue el proceso de construcción de ciudadanía en América Latina, en Colombia y su importancia en lo local, además de la participación ciudadana en dicho ámbito es importante entender el papel de la ciudadanía y la paz.

\section{Construcción de ciudadanía y escenarios de paz}

Desde el panorama de los escenarios sociales como los que tiene Colombia por cuenta de su devenir histórico, se deben buscar claridades que permitan diferenciar la aproximación desde lo conceptual y las realidades de las comunidades; 


\section{6 | Ana María Montes R., David González C. y Douglas Eduardo Molina-Orjuela La posmemoria: un elemento fundamental para la construcción de ciudadanía en Soacha}

así, para hablar de paz debemos entender el conflicto y entender que el mismo es una condición inherente a la raza humana, "se debe ser claro que pensar en la guerra no es lo mismo que pensar la paz ni que pensar la guerra significa, directa o necesariamente, pensar la paz" (Maldonado, 2003, p. 233). Sin embargo, la distinción es fundamental para entablar la discusión que hemos planteado entre la construcción y el papel de la ciudadanía en la construcción de paz a partir de la determinación de una identidad definida.

En el contexto del conflicto colombiano, los procesos de victimización han afectado directamente la construcción de ciudadanía y, de manera complementaria, la construcción de escenarios de paz a partir de la estabilidad societal del individuo. Las interacciones de violencia en el transcurso de la guerra no solo han vinculado a las partes directamente involucradas, como pueden ser grupos al margen de la ley y fuerzas del Estado, sino que también han vinculado a parte de los ciudadanos, en calidad de víctimas directas e indirectas del conflicto armado interno. Ello está soportado en la Ley 1448 de 2011, que reconoce como víctimas a "aquellas personas que individual o colectivamente hayan sufrido un daño por hechos ocurridos a partir del $10^{\circ}$ de enero de 1985, como consecuencia de infracciones al DIH [...] ocurridas con ocasión del conflicto armado interno" (Ley de Víctimas, 2011, p. 9).

A partir de ello, la identidad como factor determinante del individuo se entiende como (Castells, 1997, p. 28). Dichas fuentes de sentido, en Colombia, se han visto profundamente afectadas por el reconocimiento del individuo ante sus formas de autodeterminación cultural. Las categorías de apropiación identitaria han sido permeadas por imposiciones de criterios establecidos, en parte, por la debilidad estructural del Estado para satisfacer las necesidades primarias de los ciudadanos y la falta de garantía de la protección a los derechos humanos. Todos estos factores afectan el papel político del individuo frente a su rol ciudadano y ocasionan una ruptura en los diálogos para la construcción de la sociedad desde las mismas bases comunitarias.

Los roles, especialmente el de la autodeterminación de los ciudadanos para esclarecer sus intenciones de identificarse como miembros activos de una sociedad, han sido definidos tradicionalmente por las diferentes instituciones y organizaciones de esa misma sociedad, lo que afecta positiva o negativamente el sentido propio de los actores de individualizar e interiorizar su papel en comunidad y lleva a que se distorsione el papel del individuo como ciudadano en la construcción o participación de la ciudadanía activa que forja sentimientos de reconocimiento político y social. Es decir, el individuo no se hace partícipe de la creación de escenarios de ciudadanía por una construcción propia o colectiva de la identidad, sino 
que en muchos aspectos las organizaciones e instituciones determinan el curso de la consolidación de las identidades colectivas que determinan la ciudadanía y gestan procesos sintéticos en su desarrollo.

La identificación de la individualización debe estar formalmente ligada a la identidad colectiva, es decir, se entiende la individualización no como la aceptación del individuo en su metarrelato de autodeterminación, sino la identificación de su papel como individuo en una sociedad, en una organización política definida.

Bajo los criterios de identidad definidos por Castells, en los que se encuentra la identidad legitimadora, la identidad de resistencia y la identidad proyecto, nos vamos a concentrar en la identidad de resistencia, que va direccionada a "la formación de comunas o comunidades" (Castells, 2001, p. 31); según Castells, al identificarse directamente con la resistencia, el individuo manifiesta una contraposición a la opresión ejercida por entidades superiores o con mayores capacidades de poder, lo que lleva consigo una función de rechazo hacia un proyecto ya determinado por agentes externos que pretenden orientar la identidad de los individuos para soportar en ello la construcción del espectro social que persiguen.

Es importante identificar este término ante lo sufrido por la población afectada por el conflicto armado en Colombia ya que se caracteriza por mantener, en palabras de Etzioni, un "resentimiento contra la exclusión injusta, ya sea política, económica o social” (Castells, 1999, p. 2).

La relevancia de la identidad en el estudio de la construcción de ciudadanía y de posmemoria es tal que, aunque las diferentes entidades tengan una interacción en un sistema político, es ineludible establecer que esas entidades son compuestas por individuos y que estos van a encontrar su sentido social, histórico y vivencial en la pertenencia a esas entidades. Así es que identificar a los diferentes actores que intervienen en el conflicto armado colombiano nos conduce al descubrimiento de categorías de individualización de la violencia y a la identificación, especialmente, de las víctimas de esa violencia armada.

El reconocimiento o la autodeterminación de un grupo poblacional como víctima y su relación identitaria con una categoría geográfica o política definida, aunque se localice en su propio país, no es tan sencilla de abordar; estas categorías están plagadas de rechazo por cuenta de la entidad receptora y sus integrantes, y aún más difícil de abordar es la resistencia de la población desplazada a acoger una identidad individualizada establecida por la sociedad o la comunidad que se pretende integrar. 


\section{8 | Ana María Montes R., David González C. y Douglas Eduardo Molina-Orjuela La posmemoria: un elemento fundamental para la construcción de ciudadanía en Soacha}

Entender la conformación de los grupos de víctimas que se ubican en un espacio geográfico determinado, por ejemplo Soacha (Cundinamarca), es entender que la diversidad, como cualidad, permite "ubicar en un mismo espacio a ciudadanos con distintas experiencias de victimización, relación con el actor armado responsable de la agresión, formación académica, lugar de origen, identidad étnica o racial, filiación política, extracciones socioeconómicas y capacidad de ingresos, cultura y sector laboral, entre muchos elementos" (Bonilla, 2012, p. 312).

Ello no impide poder identificar los criterios compartidos entre los individuos que conforman esa comunidad: ellos permiten abordar de manera más activa la problemática y proyectar soluciones, especialmente frente a la construcción de identidad o a la aceptación de la identidad de la sociedad receptora. Estas van de la mano del establecimiento de condiciones de no repetición en cuanto a las condiciones que generaron el desplazamiento y la caracterización de víctima, la no revictimización, la apropiación de políticas que garanticen la subsistencia de esa población en el nuevo territorio y el amalgamamiento de las comunidades residentes y nuevas.

La proyección de una estructura societal basada en la autodeterminación es, en lo fundamental, una característica necesaria en las entidades de las comunidades desarraigadas o desplazadas por la violencia; su papel como órgano constructor de paz y replicador de la no violencia debe ser preponderante, especialmente en Colombia. Quienes hacen parte de esas comunidades han perdido muchas de sus características individualizadoras, partiendo del reconocimiento de la intimidad que se hace necesario recobrar para poder entablar un diálogo simétrico con el resto de la sociedad. "La construcción de la intimidad basada en la confianza requiere una redefinición de la identidad completamente autónoma frente a la lógica interconectora de las instituciones y organizaciones dominantes" (Castells, 1999, p. 2).

\section{Es importante resaltar que}

en Colombia coexisten zonas de paz y de guerra en un mismo espacio territorial y la dinámica de la guerra es, al mismo tiempo, la de legalidad, la formalidad y la legitimidad. La complejidad del conflicto armado consiste en el hecho de que cada agente se adapta al otro, que se ha acomodado al entorno nacional e internacional; que, a su vez, se ajusta al otro agente y así sucesivamente (Maldonado, 2003, p. 235).

Dicha complejidad y la convivencia de territorios de paz en el epicentro del conflicto han generado la necesidad comunitaria de construir paz por encima de las condiciones adversas que se puedan encontrar. Los actores más destacados 
en este papel reorganizador son las víctimas y los indígenas, quienes desde sus propios conflictos vivenciales, sus cicatrices por cuenta de hechos atroces y la escasez de respaldo institucional, han edificado espacios microsociales que permiten entender la relación entre la construcción de ciudadanía y la configuración de espacios de paz, partiendo de la corresponsabilidad de los ciudadanos en la definición de "nación" y la preservación de los mandatos humanos y constitucionales del derecho a la vida y a vivir en paz en una comunidad.

La situación de violencia en Colombia y la relación entre la ciudadanía y el conflicto cada día de se ven más ligadas al desgaste que los diferentes actores bélicos, durante sesenta años de impactos constantes a las organizaciones y bases sociales, han infringido sobre la población. "En el país se vive una situación de mezcla entre paz y guerra, con todo y que es indudable que asistimos a una degradación o un escalamiento del conflicto. La guerra parece estar imponiéndose sobre la paz, en distintas regiones de la geografía nacional" (Maldonado, 2003, p. 234).

Sin embargo, y en detrimento de la misma guerra, las comunidades violentadas por el conflicto y obligadas a desplazarse a territorios ausentes o con menor nivel de conflicto han liderado procesos de construcción de escenarios de paz que permiten reconstruir el tejido social y volcarse como nación a la esperanza de un resurgir de los poderes populares para erradicar la violencia en el país.

El origen de conceptos como "generación de no violencia", "educación para la paz", "posmemoria" y "productividad para la paz" son formas de expresión pragmática de las mismas comunidades en situación de vulnerabilidad para reconstruir su individualización y el sentido de comunidad entendido a partir del ejercicio del desarrollo y la exigencia de sus derechos ciudadanos.

Así las cosas, para esclarecer el panorama frente a la conceptualización de lo que aquí se refiere sobre "posmemoria" se debe indicar que ella está estrechamente relacionada con la superación de los escenarios de violencia o conflictos de cualquier tipo; ello en el sentido de que los intervinientes de dicha situación generan una serie de relatos a partir de vivencias y recolección de información proveniente de diversas fuentes, como puede ser el caso de otros participantes, medios de comunicación y reproducciones ficticias (literatura, teatro, cine), lo que enaltece los recuerdos que se tienen de las circunstancias vividas o también puede distorsionarlos. Este hecho se da en igual medida en víctimas, victimarios y público adyacente al conflicto. 


\section{0 | Ana María Montes R., David González C. y Douglas Eduardo Molina-Orjuela La posmemoria: un elemento fundamental para la construcción de ciudadanía en Soacha}

La posmemoria es definida como

una estructura performativa de transmisión o transferencia intra, inter y transgeneracional y una interpretación del trauma, ligado, como en algunas teorías del género, aunque no con el mismo sentido y finalidad, a esa misma performatividad que involucra no sólo imágenes y símbolos culturales, sino actos de transferencia pre-cognitivos, en el espacio familiar, que se convertirían en síntomas o, en el mejor de los casos, en expresiones estéticas, artísticas y culturales (Ciancio, 2015, p. 505).

En este sentido también se manifiesta Hirsch (1997), al ratificar el factor de la vinculación alterna de la memoria por cuenta de aproximaciones indirectas a la realidad, es decir, la transferencia generacional del relato, que tradicionalmente viene cargado de estigmas emocionales y sesgos racionales, a lo que la posmemoria pretende hacer el quite, pues es necesario partir de la consideración real de las circunstancias de violencia por cuenta de víctimas y victimarios para no caer en la revictimización o la impunidad, según el caso. Para tal momento, el relato de los actores se convierte en el factor determinante de la posmemoria, pues a partir de él se construyen nuevos paradigmas con relación a la construcción de identidades particulares y colectivas.

A partir de lo anterior se empieza a entrelazar la identidad individual y colectiva con el ejercicio de posmemoria en la construcción de sociedades o comunidades amalgamadas en el recuerdo generacional de la violencia sufrida y de los procesos de reconciliación alternos a los procesos de lo que se llama "duelo" o "superación de la tragedia", lo que puede motivar el recrudecimiento de la violencia en un escenario transgeneracional o la superación de las diferencias que generaron el conflicto y aquellas que fueron generadas por el mismo.

En todo ello se plantea la construcción de identidad común en un escenario ideal mediante buenos procesos de posmemoria para la superación de la violencia y la construcción de escenarios de reconciliación, aceptación individual y colectiva de las secuelas del conflicto y, por decirlo así, la creación de un pacto o contrato social para la no repetición aunado a la voluntad de sostenimiento de los nuevos escenarios de paz provenientes de la finalización del conflicto.

De este modo, la reorganización de la escala valorativa de las comunidades es fundamental para la construcción de identidad comunitaria,

los valores son el marco de referencia personal que nos orienta en nuestras acciones, opciones y decisiones. Cada persona tiene su propia y exclusiva escala de 
valores, edificada a partir de la relación con el entorno cultural y familiar, las experiencias vividas, la propia capacidad de análisis, las personas que se escogen como referentes, etc. De esta manera, nadie, ni personas ni instituciones, es ni puede ser neutral (Thonon, 2005, p. 10).

En concordancia con esa postura, el Observatorio de Construcción de Paz de la Universidad Jorge Tadeo Lozano ha desarrollado una categoría denominada "iniciativas ciudadanas de construcción de paz", que se refiere a todas aquellas acciones, estrategias, programas o proyectos colectivos emprendidos por miembros de la población civil que tengan como objetivo, a partir de mecanismos pacíficos, rechazar el uso de la violencia como estratagema para dirimir conflictos, emprender acciones para disminuir los niveles de esta en su entorno y abordar, desde varios campos de acción, posibles causas coyunturales y estructurales de la manifestación violenta de las diferencias, lo que promueve a mediano y largo plazo la conformación de sociedades pacíficas (Bonilla, 2012, p. 225).

En este sentido, el papel de la ciudadanía como entidad política regida por los lineamientos que le da la Constitución es garantizar, preservar, promover y difundir en la sociedad todos los actos no violentos que proyecten un escenario de paz, entendidos como espacios para la autodeterminación y la expresión sin intervención de actores que ejerzan violencia en cualquiera de sus formas.

La construcción de paz, como fomento de escenarios de expresión no violenta y convivencia, se da a partir de una cultura que promueve la pacificación; una cultura que incluye estilos de vida, patrones de creencias, valores y comportamientos que favorezcan la construcción de paz y acompañen los cambios institucionales que promueven el bienestar, la igualdad, la administración equitativa de los recursos, la seguridad para los individuos y las familias, y la identidad de los grupos o de las naciones, sin necesidad de recurrir a la violencia (Thonon, 2005, p. 10).

Así las cosas, al entender el conflicto como un factor multidimensional de generación de violencia, la paz y su construcción deben venir acompañadas de un entendimiento también en múltiples dimensiones, ante lo cual la identidad -no solo territorial, cultural o individual, sino en sentidos más amplios- debe funcionar como una manifestación de ciudadanía cohesionada en torno a esos diferente símbolos identitarios, que pueden ir desde el reconocimiento del otro como miembro activo de la comunidad hasta el reconocimiento de los símbolos nacionales, sin demeritar el papel del extranjero en la consolidación de la comunidad y su rol globalizante en la construcción de paz. 


\section{2 | Ana María Montes R., David González C. y Douglas Eduardo Molina-Orjuela La posmemoria: un elemento fundamental para la construcción de ciudadanía en Soacha}

Sin embargo, el ejercicio de la identidad ciudadana en Europa dista del desarrollado por las poblaciones latinoamericanas. La llegada tardía de la modernidad y sus implicaciones frente a la definición y construcción de ciudadanía como eje fundamental de la construcción de sociedad y esta como articuladora de la nación no han sido totalmente incorporadas a la conciencia colectiva del colombiano (afectada, por supuesto, por situaciones estructurales de violencia y pobreza extrema).

Las actuaciones de organizaciones comunitarias para restituir los derechos de la población afectada por la violencia, independientemente de los poderes estatales, en Colombia, es destacable, y es necesario adelantar esas actuaciones en puntos neurálgicos como Soacha. La lucha por la individualización -entendida según lo trabajado en este documento- y su inclusión en la sociedad permiten evidenciar que la construcción de ciudadanía y de paz han calado en la evolución política del colombiano. La receptividad de la población que ha sido ajena al conflicto hacia procesos de reconstrucción y reconfiguración ciudadana donde se incluyan desplazados y otros grupos de la sociedad permite esperar un afianzamiento de las acciones populares-ciudadanas en la construcción de la nación. De esta forma, el análisis del comportamiento, las percepciones y la heterogeneidad de las iniciativas de la sociedad civil que trabajan paralelamente con víctimas y construcción de paz nos permite identificar un proceso de avances, desafíos y riesgos: en primer lugar, existe la opción de coordinar acciones y que varios de los sectores de víctimas -en especial los que registran mayor vulnerabilidad, como desplazados, mujeres o grupos étnicos- se reconozcan como parte de un grupo social, se identifiquen y se encuentren en un conjunto de experiencias y realidades compartidas, pese a sus diferencias. En segundo lugar, se ha identificado la necesidad de reevaluar su papel en la sociedad como ciudadanos con derechos, parte integrante de una nación (Bonilla, 2012, p. 234).

\section{Conclusiones}

Dada la dimensión del desafío, las conclusiones se presentan en tres apartados: 1) en relación con la construcción de ciudadanía, 2) en relación con la importancia de efectuar ejercicios de posmemoria y arraigo territorial, y 3) en relación con el ejercicio de la ciudadanía en la población de Soacha. 


\section{En relación con la construcción de ciudadanía}

En este punto, para finalizar el análisis referente a los procesos de construcción de ciudadanía en América Latina y Colombia, es imperante traer a colación dos categorías constitutivas del concepto de "ciudadano" y las garantías estructurales para el desarrollo del ejercicio de esta condición como sujetos de derecho (que crean pautas para establecer, dinamizar y preservar la participación y deliberación como valores democráticos: nos referimos a la gobernanza y la paz territorial).

La gobernanza es un proceso relacional que pretende el establecimiento y la interlocución de acciones conjuntas entre las instituciones gubernamentales y las comunidades en el ámbito regional o local con el objeto de activar, priorizar y robustecer los planes, programas, proyectos y las políticas públicas, al tender un puente de diálogo participativo entre la institucionalidad y los ciudadanos del territorio. En el marco de la ciudadanía, la gobernanza es la encargada de la construcción de acciones y mecanismos para la participación de las comunidades en la formulación, implementación y revisión de estos procesos político-administrativos; así se garantiza de forma asertiva y dinámica una acción pública con mayor eficacia. Según Figueroa (2015),

[e]l término gobernanza comporta dos dimensiones: por un lado, la dimensión estructural y normativa referida al marco político-institucional; por otro lado, la dimensión dinámica, referida a las acciones de los actores [...]. La gobernanza no se refiere sólo a la organización gubernamental, sino a un conjunto de interacciones que entrelazan una serie de actores estratégicos, comprende al gobierno (en todos sus niveles), a los actores de la sociedad civil, el mercado y demás organizaciones sociales, en todos los ámbitos de la acción pública (p. 72).

Ahora bien, las dimensiones de la gobernanza, de cara a la construcción de ciudadanía, como lo refiere Figueroa (2015), están supeditadas a las capacidades del escenario territorial para instar al establecimiento y la defensa de vasos comunicantes de manera estratégica y empática; dicha sinergia debe desarrollarse en contextos que permitan gestionar las conflictividades de manera pacífica y tener condiciones para la protección de los derechos de los actores involucrados.

En esa medida, la paz territorial, más allá de ser un concepto o estar enmarcada en una tipología de paz, se refiere a una "idea fuerza", como lo acuñó Jaramillo (2015), que trasciende a un enfoque trasversal sobre los procesos de gobernabi- 


\section{4 | Ana María Montes R., David González C. y Douglas Eduardo Molina-Orjuela \\ La posmemoria: un elemento fundamental para la construcción de ciudadanía en Soacha}

lidad y gobernanza desde los escenarios regionales, locales, barriales y comunitarios donde se esgrimen herramientas y dispositivos endógenos para construir paz, teniendo como piedra angular la participación y el empoderamiento de los ciudadanos al integrar las necesidades y los derechos de las comunidades.

Vargas, Sánchez \& Botero (2016), refiriéndose a la paz territorial, dicen:

Existen diversas formas de entender y ordenar las realidades y experiencias que los pobladores viven cada día en sus territorios, así como distintas maneras de explicar las causas de la violencia, la pobreza, los conflictos, y las vías para resolverlos y caminar a partir de las propias necesidades e intereses para construir la vida querida [...]. se entiende por conocimiento para la paz las experiencias, iniciativas y [los] proyectos vividos y reflexionados por los pobladores que contribuyen al desarrollo y la convivencia en el territorio (Vargas, Sánchez \& Botero, 2016, p. 6).

Finalmente, la consecución de ejercicios de gobernanza y paz territorial para la construcción de ciudadanía constituye un reto ineludible y titánico para desarrollar una condición de ciudadanos con pluralidad, inclusión, garantías sobre sus derechos y la posibilidad de participar de manera activa y concienzuda. No obstante, en el contexto de América Latina y Colombia hay una multiplicidad de iniciativas que han sido invisibilizadas, y estas, si se quiere avanzar en términos de aspirar a una ciudadanía cosmopolita, deben ponerse como paradigma desde lo local hasta lo central. De ahí la importancia de la posmemoria para integrar realidades y escenarios que históricamente han estado resquebrajados.

\section{En relación con la importancia de efectuar ejercicios de posmemoria y arraigo territorial}

Con la pretensión de identificar el papel que tienen las víctimas del conflicto armado en Colombia en la construcción de paz y ciudadanía, se debe integrar el reconocimiento de identidad como factor determinante desde lo individual y lo colectivo. El individuo se presenta como la base estructural de las apuestas frente a escenarios de paz, reconciliación y no repetición, especialmente aquellos que han sufrido de manera directa o indirecta los horrores de la guerra. Es la población víctima la que, por cuenta del empoderamiento y la progresión de procesos de posmemoria, ha podido consolidar escenarios positivos de ciudadanía, lo que se consolida como la piedra angular de la construcción de nuevos escenarios de paz en los territorios receptores. 
Después de mencionar los diferentes tipos de identidades, se optó por la denominada "identidad de resistencia", que describe la construcción de comunidades como una reacción a procesos de opresión, al rechazar niveles de jerarquía superiores en la sociedad. Esto se relaciona con las vivencias acaecidas en América Latina por cuenta de los escenarios políticos dictatoriales y las dificultades en la implementación de la democracia. También se relaciona directamente con las víctimas frente al proceso de rechazo social que viven en entornos alejados del conflicto del que provienen, es decir, se ha identificado que las víctimas han optado por el desarrollo de identidades de resistencia frente a las poblaciones receptoras, lo que crea espacios de construcción ciudadana que, aunados a la implementación de procesos de posmemoria, redundan en el incremento de pertenencia a la colectividad y al territorio.

Aunque se presentan dificultades individuales y colectivas de las víctimas desplazadas para integrarse a los territorios y las comunidades receptoras, la actuación de estas últimas en el proceso de estabilización de la población en condición de vulnerabilidad ha sido motivado por el empoderamiento de las víctimas y la percepción que generan frente a la apropiación y el respeto de los bienes comunes.

Todo ello indica que existe un rol dinamizador de las víctimas en la construcción de escenarios de paz en los territorios receptores, fortalecido por el buen desarrollo de procesos de posmemoria que evitan la repetición y favorecen el perdón como articuladores en la construcción de una paz estable y duradera. Estas son iniciativas ciudadanas de construcción de paz fundamentadas en los diferentes criterios y valores sociales donde el rechazo de la violencia se configura como una acción ciudadana y reivindica la identidad restablecida en las comunidades tanto vulnerables como receptoras, lo que crea una integración y mitiga los escenarios de exclusión social.

\section{En relación con el ejercicio de la ciudadanía en la población de Soacha}

Dadas las características de la ciudadanía del municipio de Soacha, las condiciones históricas de vida se identifican desde dos diferentes ópticas: la de los pobladores nativos, cuyas condiciones socioeconómicas muchas veces han labrado un camino de necesidad y pobreza; y la de los casos de desplazados por el conflicto armado interno que llegan a hacer parte de la población soachuna. Además de contemplar las condiciones estructurales de la población nativa, debemos sumar 


\section{6 | Ana María Montes R., David González C. y Douglas Eduardo Molina-Orjuela La posmemoria: un elemento fundamental para la construcción de ciudadanía en Soacha}

la condición de víctimas de un conflicto que los llevó a desarraigarse de su población de origen, lo que convierte la categoría histórica de "las vivencias" en un escenario idóneo para esclarecer procesos de posmemoria, pues la "transgeneracionalización" del conflicto tiene efectos multiplicadores de manifestaciones sociales de las conductas individuales de las víctimas.

El escenario de la erradicación del conflicto interno armado o posacuerdo plantea la oportunidad para la correcta gestión de la posmemoria de la población vulnerable del municipio. El desplazamiento del que fueron objeto las personas y los vejámenes que muchas sufrieron, presenciaron o conocieron en sus núcleos familiares y comunitarios, por cuenta de un ejercicio de memoria tradicional ejerce un gran influjo de construcción de la identidad individual y colectiva en las siguientes generaciones. Como ejercicio de posmemoria, el reconocimiento de los victimarios, la aceptación social como víctimas, el acompañamiento estatal y gubernamental y la inserción decidida en la comunidad receptora como verdaderos ciudadanos con derechos y deberes claros permitirá que se inicie un proceso de claridad y perdón frente a los hechos históricos, el origen y las causas que las conductas violentas generaron, junto con el reconocimiento y la no repetición de las mismas. En conjunto, estos serán factores determinantes para el buen fin del proceso para la construcción de una paz estable y duradera.

En este sentido, se hace necesario una atención especial a la población conformada por nińos, nińas, jóvenes y adolescentes, quienes hacen parte de las familias en condición de vulnerabilidad y que han sufrido directa e indirectamente por el conflicto armado en cualquiera de sus acepciones. Ellos, al ser los reales ejecutores de la posmemoria como capacidad de construcción de escenarios de perdón y restitución de condiciones humanas en las víctimas, serán la generación que, al reconocer y aceptar las condiciones del conflicto y su papel en el mismo, evitarán la transmisión de sentimientos que lleven a la revictimización o a la gestación de nuevas condiciones de conflicto en su misma generación y en las que le siguen.

Así, es necesario que, por medio de ejercicios de posmemoria en la población más joven, entre los ciudadanos más vulnerables, se evite el flujo histórico del resentimiento y la revictimización que terminan en la escalada de nuevas conductas bélicas que producen más víctimas como un ciclo vicioso. 
Ana María Montes R., David González C. y Douglas Eduardo Molina O. | 147 La posmemoria: un elemento fundamental para la construcción de ciudadanía

en Soacha

\section{Referencias}

Abasolo, O. \& Montero, J. (2012). Guía didáctica de ciudadanía con perspectiva de género: igualdad en la diversidad. Madrid: Fuhem Social.

Alcaldía Municipal de Soacha (2016). Indicadores poblacionales del Municipio. Indicadores poblacionales del Municipio, volumen (N/A), pp. N/A. Recuperado de https:// bit.ly/2OsPujN

Alcaldía de Soacha (2016, 15 de junio). Recuperado de http://www.soacha-cundinamarca.gov.co/indicadores.shtml\#poblacion.

Alvarado, S. \& Carreño, M. (2007). La formación ciudadana: una estrategia para la construcción de justicia. Revista Latinoamericana de Ciencias Sociales, 5, pp. 1-15.

Angulo, M. (2013). Construcción de ciudadanía y democracia liberal en Colombia (Tesis de grado, Universidad Colegio Mayor de Nuestra Señora del Rosario, Bogotá, Colombia).

Beuchot, M. (1997): Tratado de hermenéutica analógica: hacia un nuevo modelo de interpretación, México D. F.: Ítaca 2000.

Bodenheimer, E. (1940). Teoría del Derecho. Nueva York: McGraw-Hill.

Bonilla, L. C. (2012). Tendencias e identidades de las iniciativas ciudadanas de construcción de paz y víctimas de la violencia en Colombia. En O. D. Paz, Víctimas: miradas para la construcción de paz (pág. 312). Bogotá: Universidad de Bogotá Jorge Tadeo Lozano.

Cámara de Comercio de Bogotá (2010). Plan de competitividad para la provincia de Soacha. Bogotá: Cámara de Comercio de Bogotá

Cardona Giraldo, J.; Barreto, A.; Cardona Giraldo, J.; López, H. \& Narváez, A. N. (2011). Individuo, comunidad y solidaridad. Bogotá: Fundación Universidad Autónoma de Colombia.

Cardona, Á. E. M. (2014). La ciudadanía: un deber planetario. Semestre Económico, 17(35), pp. 193-204. Recuperado de https://search.proquest.com/docview/16951 64837 ? accountid $=13250$.

Castells, M. (1997). La era de la información: economía, sociedad y cultura. El poder de la identidad. México: Siglo veintiuno editores.

_ (1999). Globalización, identidad y Estado en América Latina. Flacso Andes. Recuperado de http://www.flacsoandes.edu.ec/sites/default/files/agora/files/1266426228. globalizacion_castells.pdf. (2001, 24 de julio). Globalización y antiglobalización. El País.

Ciancio, B. (2015). ¿Cómo (no) hacer cosas con imágenes? Sobre el concepto de posmemoria. Constelaciones - Revista Teórica crítica, (7), pp. 503-515.

Cortina, A. (1997). Ciudadanos del mundo: hacia una teoría de la ciudadanía. Madrid: Alianza Editorial.

Donoso, S. (2015). El desafío de la participación ciudadana: algunas reflexiones sobre la experiencia chilena. Políticas y líneas de acción - CLACSO. 6 - 10.

Durston, J. (1996). Limitantes de ciudadanía entre la juventud latinoamericana. Revista Iberoamericana de Juventud, (1), 1-4

Figueroa, R. D. (2015). La gobernabilidad local en la democracia contemporánea. Cuadernos de Administración, 21(34), pp. 61-96. 
148 | Ana María Montes R., David González C. y Douglas Eduardo Molina-Orjuela La posmemoria: un elemento fundamental para la construcción de ciudadanía en Soacha

Font, J. (2004). Participación ciudadana y decisiones públicas: conceptos, experiencias y metodologías. En talleres de participación y ciudadanía. Jerez de la Frontera, 1, 23-42.

Gallego García, G. M. (2016). Perdón y proceso de paz en Colombia. Revista Nuevo Folo Penal, 12, pp. 159-180.

Galván, V. (2011). La ciudadanía en el siglo xxi: una categoría multidimensional. Revista digital del centro de profesores de Alcalá de Guadaíra, pp. 1-13.

García, M. (2000). ¿Ciudadanía avergonzada? Democracia local y construcción de ciudadanía: el caso de las juntas administradoras locales de Bogotá. Buenos Aires: Consejo Latinoamericano de Ciencias Sociales.

Gobernación de Cundinamarca (2009). Línea base para el estudio prospectivo del municipio de Soacha. Soacha: Gobernación de Cundinamarca.

Hirsch, M. (1997). Family frames: photography, narrative and postmemory. United States of America: Harvard University Press.

Levine, D. H. \& Molina, J. (2011). The quality of democracy in Latin America. Boulder: Lynne Rienner Publishers.

Ley de Víctimas, Ley 1448 de 2011 (Congreso de la República de Colombia, 10 de junio de 2011).

Mainwaring, S. (2006). The crisis of representation in the Andes. Journal of Democracy, pp. 13-27.

Maldonado, C. E. (2003). Biopolítica de la guerra. Bogotá: Siglo del hombre editores.

Médicos Sin Fronteras (s. f.). Altos de Cazucá, hasta cuándo en el olvido. Soacha: Médicos Sin Fronteras.

Molina Orjuela, D. E. \& Córdoba, S. A. C. (2012). Movimientos sociales: visiones de alternatividad política desde Sur y Centroamérica. Casos: Bolivia, Ecuador, Brasil y México. Ars Boni et Aequi, 8(2), p. 211-250.

Molina Orjuela, D. E. (2014). Cultura política, democracia y participación: más allá de las elecciones universitarias práctica de la Universidad de San Buenaventura. Ciencia y Poder Aéreo, 9(1), pp. 183-192.

Montes Ramírez, A. (2012). La comunicación como factor de efectividad en la política pública; el caso de la regulación del ejercicio profesional de la abogacía. Bogotá: Universidad del Rosario.

Montes, A. M.; González, D. \& Molina, D. (2017). Entrevistas a comunidad en Soacha. INV-DIS 2477, denominada "Regulación ambiental y paz; una visión de la participación de los jóvenes en el post-acuerdo para la protección del medio ambiente", Cajicá.

Neira, A. (2018). En 2017 aumentó el abismo entre millonarios y pobres. El Tiempo. Recuperado de https://www.eltiempo.com/economia/sectores/desigualdad-aumento-en-el-2017-y-la-brecha-entre-ricos-y-pobres-175900.

PNUD (2004). Informe sobre desarrollo humano. Sostener el progreso humano: reducir vulnerabilidades y construir resiliencia. Washington: Communications Development Incorporated.

Quíles Esteves, L. (2014). Hacia una teoría de la posmemoria. Reflexiones en torno a las representaciones de memoria generacional. Historiografías, (8), pp. 57-75.

Quintero Jiménez, D. A. (2013). Estudio de la participación ciudadana en la ocupación informal del territorio. Estudio de caso: Comuna 4 de Soacha, 2008-2011. Bogotá: Universidad del Rosario. 
Ana María Montes R., David González C. y Douglas Eduardo Molina O. | 149 La posmemoria: un elemento fundamental para la construcción de ciudadanía

en Soacha

Ramírez, G. (2017, 17 de octubre). Entrevista a Líder Comunal. (D. González, entrevistador).

Sojo, C. (2002). La noción de ciudadanía en el debate latinoamericano. Revista de la CEPAL, 76, pp. 25-38.

Thonon, M. C. (2005). Introducción de conceptos: paz, violencia, conflicto. Barcelona: Escola de Cultura de PAU.

Torres, M. (2001). Participación ciudadana y educación: una mirada amplia y 20 experiencias en América Latina. Punta del Este: Organización de Estados Americanos.

Vargas, M. F.; Sánchez, S. \& Botero, S. H. (2016). Mapas para la paz, desarrollo y paz territorial. p. 6.

Velázquez, F. \& González, E. (2003). ¿Qué ha pasado con la participación ciudadana en Colombia? Bogotá: Fundación Corona. 